\title{
ПОСТАНТРОПОЛОГИЧЕСКИЙ ВЕКТОР ГЛОБАЛЬНОГО РАЗВИТИЯ: К ЛОГИКЕ НЕЛИНЕЙНОЙ ПРОЦЕССУАЛЬНОСТИ
}

\author{
Муза Д. Е.
}

\begin{abstract}
Статья посвящена проблеме перехода человечества $\kappa$ постантропологической перспективе, который рассматривается под углом зрения утраты современным человеком его сущноостных признаков и их замены на «плавающие» характеристики. Цель статьи - рассмотреть нелинейную драматургию этого перехода под углом зрения двух катализаторов: современных технологий и рыночных игр. Причем такая интерпретация опирается на представление о том, что технология и экономика как онтологические (институциональные) размерности современного социума могут быть представлень через контрапункт, как и через эквипотенииальную систему техноэкономику.
\end{abstract}

Ключевые слова: распад сущности Ното, постчеловек, техноэкономика, нелинейность, постантроподинамика.

The article is devoted to the problem of the transition of mankind to the postanthropological perspective, which is viewed from the point of view of the loss of its essential features by a modern person and their replacement by «floating» characteristics. The purpose of the article is to consider the nonlinear dramaturgy of this transition from the point of view of two catalysts: modern technologies and market games. Moreover, such an interpretation rests on the idea that technology and economy, as ontological (institutional) dimensions of modern society, can be represented through counterpoint, as well as through equipotential system - technoeconomic paradigm.

Keywords: decay of Homo essence, post-human, techno-economic paradigm, nonlinearity, post-antropo-dynamics.

Современные дискуссии о человеке все чаще акцентируют факт трансгрессии этого существа к новым онтологическим рубежам и интригам. Думается, что это вовсе не случайно, поскольку на повестке дня тенденция окончательной утраты Ното своего главного, субстанциального индикатора и замены его на мультимодальные структуры и прогрессирующие конфигурации функционалов.

Речь идет о «человеке Тьюринга», «кибернафтах», e-homo, Nano-sapiens'e, «бионических ангелах» и пр. Нередко можно слышать о наступлении «эпохи нового тела», преодолении биосферной и социосферной «ограниченности», разрушении прямолинейности и подчеркнутой ущербности фило-, онто- и социогенетики. Между тем новая эпоха обещает быть эпохой улучшенного вида или же его радикальной трансформации, причем в аспекте монадности, размещенной в пост-

* Муза Дмитрий Евгеньевич - д. ф. н., профессор, член-корреспондент Крымской академии наук, начальник научного отдела ГОУ ВПО «Донецкий педагогический институт» MOH ДНР. E-mail: no_donpi@mail.ru.

Век глобализации 1/2018 49-59 
биосферном и информационно-цифровом мирах с принципиально непредустановленной гармонией.

Иначе говоря, достаточно определенный образ человека поставлен постмодернистской культурой с ее «техногнозисом» и «техно-аутопоэзисом» под радикальное сомнение, а взамен предлагаются варианты его черновиков, прямо или косвенно указывающих на тенденцию перехода в состояние «пост-». Конечно, у данной трансгуманистической тенденции есть свои объективные предпосылки: «Лавина ущербных и немощных детей нарастает практически во всех индустриально развитых странах, что уже ассоциируется с начавшимся вырождением кроманьонца как вида... Не исключена уже социогенетическая смена его постчеловеческим разумным существом» [Демиденко 2003: 151].

Однако такая общая проблемная рамка нуждается в концептуальной конкретизации, что, собственно, и предпринимается в настоящей статье. В ней преследуется цель - рассмотреть антропологический переход, его нелинейную драматургию под углом зрения двух катализаторов: современных технологий и рыночных игр. Причем такая интерпретация опирается на представление о том, что технология и экономика как онтологические размерности современного социума могут быть представлены через контрапункт и через эквипотенциальную систему - техноэкономику.

Если обратиться к современной рефлексии этого перехода, то в ее зеркале обнаруживается ряд любопытных обстоятельств. Например, украинский автор В. Г. Табачковский убедительно показал метаморфоз от классического (моносущностного) понимания человека к нынешним вариациям его полисущностной, дискретно организованной природы [Табачковський 2005]. В этом же духе, но иными методологическими акцентами («природа человека является многоуровневой, а его сущность - многомерной») выразил свою позицию дуэт известных российских философов - С. А. Лебедева и Ф. В. Лазарева [Лебедев, Лазарев 2010: 34]. Но правоту этих медитаций подтверждают и более конкретные (прицельные) исследования.

К примеру, Ю. Хабермас, много говоривший о «генно-технологической самоинструментализации» человека, не видел в «натуралистическом футуризме» чегото странного, ведь ранее натурализм физики, неврологии и эволюционной биологии преодолел классические монообразы человека, созданные религией и метафизикой [Хабермас 2002: 107]. Правда, нынешний этап «либеральной евгеники» несет в себе ряд этических дилемм, в конце концов возвращающих нам прежний облик Ното. В свою очередь, Ф. Фукуяма указывает на биотехнологическую революцию, то есть на открытия нейрофармакологии и молекулярной биологии как главные инструменты конституирования постчеловеческого будущего. Именно чрезвычайная «пластичность» человеческой природы, открытая наукой и подпитываемая новыми формами свободы, открывает новое измерение истории [Фукуяма 2004: 305-308].

Однако тональность дискурса о человеческо-постчеловеческом уделе может быть и другой. На ином, а именно - сверхдинамичном глобально-социокультурном аспекте утраты человеком себя делает акцент О. Тоффлер: «...по мере разрушения научных, экономических, политических и других границ размывается само понятие того, что значит быть человеком» [Тоффлер 2008: 531]. Это размывание, с чем можно согласиться, имеет свои эпистемологические причины: мы 
являемся свидетелями и соучастниками изменения типа рациональности, а именно - использования такого способа мышления, который имеет сугубо функциональные отношения и количественные показатели бытия [Муза 2013: 72-73]. В этом створе и ищется единая «ментальная» формула, обеспечивающая присутствие постчеловека в универсуме.

В данном контексте наиболее сильным аргументом, указывающим на финализм начавшегося процесса, выступает аргумент к Сингулярности: расчеты Г. Д. Снукса, А. Д. Панова и Р. Курцвейла показали, что сократившиеся периоды между глобальными фазовыми переходами в истории биосферы и антропосферы плюс увеличение скорости глобальных изменений неизбежно приведут к появлению «великого эскалатора», устраняющего экономические, экологические и прочие диспропорции. И с «бессмертным носителем разума» (!) [Назаретян 2017: 299-344].

Но все же онтологические размерности в рамках постантропологического дискурса выступают как базисные, поскольку они задают структурно-топологические, ритмические и семантические координаты жизни. В отношении прояснения наличной онтологической специфики несомненный интерес представляют работы двух российских авторов - С. С. Хоружего и В. А. Кутырева.

Так, С. С. Хоружий прямо указывает на причины происходящего, то есть на изменение человеческого бытийного горизонта: «Генетические и гендерные эксперименты, практики трансгрессии (включая феномен суицидального терроризма), экстремальные психопрактики, “кислотные” и виртуальные практики...- весь этот спектр явлений, как мы говорили, выражает некоторые перемены с Человеком. Что это за перемены, как можно их охарактеризовать? В первую очередь, во всех перечисленных явлениях видна одна общая черта. Если и не все они имеют непосредственно кризисный и катастрофический характер, то заведомо все имеют характер предельный: все они суть такие явления и практики, в которых Человек устремляется к пределу, к границе своих возможностей, самого горизонта своего существования: к той области антропологических проявлений, в которой начинают изменяться фундаментальные предикаты способа существования человека и которую естественно называть антропологической границей. Далее, надо обратить внимание на беспрецедентное множество и разнообразие, предельную же широту диапазона совершающихся предельных явлений. Это свидетельствует о том, что "предельность" - погруженность в предельные практики и стратегии, акции, формы поведения - становится для Человека самоценностью, самоцелью. Человек стремится актуально осуществить и испытать все и любые в принципе возможные предельные проявления, стремится активизировать, актуализовать весь их существующий круг, репертуар. Эту особенность и можно считать общей определяющей чертой той антропологической динамики, которая обнаруживается во всем комплексе новых характерных явлений антропологической ситуации наших дней» [Хоружий].

В свою очередь, В. А. Кутырев в своем триптихе показал: схватка «естественного» и «искусственного», борьба «культуры» и «технологии» трансформировались в борьбу человека со своим иным. Причем он заявляет о «Великой, всеобъемлющей нигилистической революции», которая не только удалила «файл» Бытия, заменив его возможными (виртуальными) мирами, а на место Homo sapiens воздвигла «Computer science искусственный». Причем эта революция происходит 
под лозунгом «инонизма», то есть достижения мира количества, онтологии «чужого» и нигитологии, наконец, «идеологии отказа человеческого вида от продолжения своего рода» [Кутырев 2009: 144].

Как видим, обрисованные трансформации человека и его мира находят в современных дискурсах свое определенное выражение. Но в данной ситуации, как представляется, нужна дополнительная рефлексия, осуществляемая с целью выработки метапозиции, связанной с синергетическим пониманием происходящего.

Итак, если конкретизировать разнообразные дискурсы через идею перехода (поворота) в новую стадию, то напрашивается следующее: a) в настоящий момент «снята» привычная (психофизиологическая) онтология человека - онтологией постлюдей, в которой обретены новая телесность и гиперинтеллект, а также созданы невиданные ранее функционалы и установлены иные типы связей в рамках заметно трансформированной диметрии; б) конституирован оптимальный тип реальности - виртуальная реальность, которая онтологически независима от предметного мира и его модусов и вообще выступает в качестве смыслового экстракта постчеловеческого бытия; в) радикально изменен хронотоп бытия пост-һото, причем таким образом, что привычным метрикам в «сетевом сообществе» и «обществе потребления» нет места, а взамен предложены сеть техно-виртуальных топосов и кластер «вечного настоящего»; г) артикулированы и методично культивируются «нечеловеческие» иели, интересы $и$ изенности. Все бы хорошо, но этот суммативный трансгрессирующий феномен на глазах становится феноменом глобального масштаба и уровня сложности.

Нужно заметить, что проблема человека нередко осознается в виде проблемы его адаптации к современным, радикально меняющимся условиям жизни. Формально это справедливо. Еще в советской глобалистике ей было уделено внимание под углом зрения демографии, биологии и социологии (работы И. Т. Фролова, В. В. Загладина, А. Н. Чумакова и др.). Сегодня она находится в фокусе внимания различных специалистов - эволюционной биологии и психологии, этологии и кибернетики, когнитивной неврологии и социологии, антропологии и этики. При этом, как правило, указывается на ее позитивное звучание. Но осмысление проблемы человека предлагается также вести средствами философии, которая привыкла видеть всякую проблему не только с лицевой, но и с изнаночной стороны. Поэтому сегодняшний посыл философии - установить и описать так называемые «антропологические ловушки» (кризис идентичности, медийное манипулирование сознанием, дегуманизация, гегемония масскультуры) - выглядит оправданным. Последние связаны: а) с реализацией уродливых социально-антропологических доктрин; б) разрушением базисных определений Homo sapiens; в) осуществлением негативных цивилизационных, геополитических процессов, в том числе глобализации [Лазарев 2008: 39].

Проще говоря, философия не может миновать тот факт, что антропологическая эволюция (вплоть до ставших очевидными тупиков и ловушек) своим динамизмом обязана Западу ${ }^{1}$, точнее, западной цивилизации модерна и ее нынешней трансформации в постмодерн.

${ }^{1}$ В этом отношении справедлива ремарка П. Тейяра де Шардена о том, что «ведущая ось антропогенеза прошла через Запад», поскольку «все, что было давно известно в других местах, приняло окончательное человеческое значение, лишь войдя в систему европейских идей и европейской деятельности» [Тейяр де Шарден 1987: 170]. 
Нужно заметить, что к такому пониманию, а именно: «антропологического излома», «антропологического тупика», «антропологического кризиса» - пришли не сегодня. В наиболее общем виде эта проблема была поставлена О. Тоффлером в его программной работе «Футурошок» (1972): в результате встречи с радикальными переменами в жизненном укладе, формах, ритме возникло особое психобиологическое состояние человека - боязнь перемен. При нарастающих изменениях во внешней среде происходит изменение психического состояния людей (ощущения «бомбардированы», индивиды пребывают в состоянии «информационной перегрузки», решения принимаются в состоянии стресса, без должной рефлексии и оценки). В результате мы можем наблюдать миллионы (если не миллиарды) «жертв футурошока». Правда, Тоффлер интерпретировал перемены как вторжение будущего в настоящее и на этом основании пытался построить «мировую теорию адаптации». Она предполагала управление изменениями в сторону смягчения их последствий, демократизацию самих методов и пересмотр всех (в том числе технократических как неадекватно представляющих цели человечества) ориентаций в будущее. Однако, как мы знаем теперь, вторжение будущего ${ }^{2}$, проходившее без надлежащей амортизации, как раз и обернулось неисчислимыми жертвами, в том числе потому, что темпы научного, технологического и социального изменения затронули «химическую и биологическую стабильность человеческой расы» [Тоффлер 1997: 276].

В немалой степени трансформации вида Ното были ускорены в 90-е гг. $\mathrm{XX}$ столетия. Эта проблема зазвучала иначе, и прежде всего в связи с биотехнологической револючией (разработка и внедрение в практику новых лекарственных средств, успехи в исследовании стволовых клеток, генная инженерия). Считается, что именно с ее помощью открылась возможность заняться евгеникой, то есть практическим улучшением человеческой природы, исправлением изъянов предшествующих ступеней антропологической эволюции.

Но и это еще не все, поскольку параллельным курсом осуществлялась информационная революиия, которую удачно предвосхищали в своих трактатах такие разные авторы, как Н. Винер и М. Маклюэн. Тем не менее ее разбег и нынешние формы чаще всего осмысливаются стандартно, то есть посредством указания на взрывоподобный рост количества информации (за 10 последних лет вычислительная мощность увеличилась в 1000 раз); или делаемого ударения на специфике информационного обмена, в отношении которого не действует принцип сохранения, присущий веществу и энергии [Делягин 2008: 53]; или фиксации того обстоятельства, что «компьютер не только революционализировал посредством электронных соединений нашу нематериальную жизнь, он безвозвратно изменил и нашу материальную жизнь» [Дери 2008: 12]. Речь по большому счету идет об эмпирических и структурных моментах, таких как техно-арт, техноспектакли, технои биомузыка, кибернетический боди-арт, киберсекс, киборгизация телесности, и, конечно, о новых субъектах типа техно-яппи, киберпанков, киберхиппи, «терминаторов», виртуальных двойников и т. д. ${ }^{3}$

\footnotetext{
${ }^{2}$ Не секрет, что часть интеллектуального истеблишмента США озабочена так называемыми неконтролируемыми факторами: сегодня, считает Р. Шапиро, «исторически неконтролируемым фактором являются неожиданные технологические прорывы» [Шапиро 2009: 449].

${ }^{3} \mathrm{~B}$ качестве примера хочу привести чрезвычайно показательную выставку под названием «Decode: прикосновение к цифровому искусству», прошедшую в Лондоне (2009), Пекине (2010) и Москве (2011).
} 
Конечно, эти рамочные аспекты важны для понимания исследуемой трансформации, но они охватывают лишь ее внешнюю сторону. В более конструктивном направлении (от явлений - к сущности) пытается идти американский публицист Э. Дэвис и российский ученый В. А. Кутырев. Первый делает акценты на техногнозисе как ключевом параметре современного бытия, в частности на создании нового мифа об информации, электрическом мозге и бесконечных базах данных, компьютерном прогнозировании и гипертекстовых библиотеках, реалистичных медиаснах и всепланетарной экранной культуре, связанной воедино глобальной коммуникационной сетью [Дэвис 2008: 15]. Второй говорит о перейденном «Рубиконе антропологии», то есть об умалении онтологии человека за счет достижений хай-тек и биотехнологий и приведении ситуации к полной деэволюции человеческой экзистенции [Кутырев 2010: 69-75]. Разумеется, эти ценные наблюдения нуждаются в корректной интерпретации, поскольку инфляция человеческой сущности поставлена в зависимость от познавательных и бытийных паттернов.

Делая небольшое методологическое отступление, хочу подчеркнуть то обстоятельство, в соответствии с которым две ведущие тенденции современного бытия - последовательная технологизация человека (= его дисфункция как человека) и спорадическая гуманизация техносферы (установление человекоразмерных смыслов) - не только не совпадают, но и во многом контрадикторны. Очевидно, что пришел период их дивергенции, а не образования гомеостазиса ${ }^{4}$. Но как быть с тем фактом, что прежние этапы эволюции Ното предполагали борьбу с возрастающим хаосом, как внутренним, так и внешним?

Итак, нужно заметить, что природа человека в мировых религиях, а тем более в западной науке и философии модерна (то есть XVI-XX столетия), - величина постоянная ${ }^{5}$. Ситуация меняется к концу XX в., когда происходит серьезный социокультурный сдвиг в представлениях о ней, вызванный упомянутыми факторами. В конце концов появляется идея о нежесткой, непредзаданной природе человека, которую можно деформировать в любом удобном направлении. Разумеется, наука, рынок и СМИ здесь должны сделать свое эпохальное дело, внушив человеку комплекс недостроенности, ущербности. Определенная ставка здесь делается на общественные движения и организации (например, Всемирную ассоциацию трансгуманистов - WTA), отстаивающие принципы изменения эволюции человека и появления его нового, более совершенного вида.

\footnotetext{
Мир будущего, который был представлен ее устроителями, можно охарактеризовать как прекрасный и безумный одновременно.

${ }^{4}$ Современная синергетическая версия бытия человека не только усиливает эффект неопределенности, но и оправдывает его. Здесь легитимен тезис о том, «что путь творчества состоит в том, чтобы отдать себя во власть хаосу для овладения им, подчиниться хаосу, получив возможность создать из него изящную структуру» [Князева 2000: 88]. Этот шаг в бездну, который следует после шагов по бесконечной Вселенной, ГУЛАГу и Освенциму, тем не менее опирается не только на идею монолитности человека, но и на его подчеркнутую теургичность. Но Е. Н. Князеву, по-видимому, ничему не научил опыт нескольких антропологических катастроф XX в., его, Ното, отнюдь не мифологическое оборотничество! Как здесь не озаботиться тем, что Голем, Фауст, Übermensch, Смердяков, Шигалев, Эдип, Орфей и Нарцисс были актуализированы в виде принципиальных, судьбоносных жестов. Если к ним присовокупить киборговую проекцию человека, то складывается вполне рельефная картина антроподинамики.

${ }^{5}$ «В принципе, - пишет российский философ П. С. Гуревич, - под “природой человека” подразумеваются стойкие, неизменные черты, общие задатки и свойства, выражающие его особенности как живого существа, которые присущи хомо сапиенс во все времена независимо от биологической эволюиии и исторического прочесса (курсив мой. - Д. М.)» [Гуревич 1999: 60].
} 
Тем не менее есть серьезные причины думать об этой проблеме иначе. Обеспокоенность прохождения именно такой, либерально организованной траекторией вовсе не напрасна, поскольку «самоинструментализация вида» (Ю. Хабермас) несет в себе новые противоречия и проблемы. Например, этическую дилемму видят в том, что: а) генетически запрограммированные личности уже более не рассматривают себя как безраздельных авторов своей собственной истории жизни; б) в отношениях с предшествующими поколениями они уже более не могут без каких-либо ограничений рассматривать себя в качестве равных по происхождению личностей [Хабермас 2002: 93].

Но на фоне новых перспектив эти дилеммы кажутся чем-то акцидентальным. Не секрет, что разнообразные перспективы: перспектива киборга (соединение «естественного» человека и техногенных деталей), перспектива полностью искусственного существа (создание Франкенштейна), перспектива создания «сапиентиссимуса» (сверхразумного организма); перспектива «улучшенных людей» (частичный андроид) - дают колоссальный заряд оптимизма и уверенности [Буровский 2008]. Конечно, эти перспективы опираются, с одной стороны, на факт ухудшающейся генетики вида Ното, а с другой - на потрясающие успехи современной науки и техники. Но масштаб проблемы не исчерпывается такими ее границами. Скорее наоборот, он только ее минимизирует и затемняет.

Чтобы понять это, нужно обратиться к услугам философской антропологии, которая имеет дело с «сущностью и сущностной структурой человека» (М. Шелер). По большому счету в человеке заложены и в разной степени развиты три программы: биологическая, сочиальная и духовная. Спор о первенстве какойнибудь одной - это сквозная проблема всей обозримой истории и культуры, поскольку за каждую программу в разные эпохи ратовали религия, философия, искусство и наука. У них у всех находились аргументы в пользу редукции человека либо к биологическому, либо к социальному, либо к духовному основанию. Но на самом деле современная ситуачия человека свидетельствует о том, что за основу ее понимания и трансформации берется человек западного типа, не мыслящий себя вне долголетия, комфорта, достатка и, конечно же, процедуры самоуправления своим собственным развитием. При этом в расчет не взяты антропологические сюжеты иных цивилизаций, где вообще по-другому акцентирована и представлена сущность человека, а также указаны варианты ее проявления в социуме и во взаимодействии с космосом. В терминах современного гуманитарного знания - выстроены формулы идентичности.

Так, в Китае человеческая сущность соотнесена с Дао (Законом), с природой и развивается циклично; в Индии она находится в зависимости от многообразных высших и низших сил, но сопряжена с универсальным духовным принципом Брахманом. В исламской цивилизации человек - творение Всевышнего, а в православной - отображение Святой Троицы. И только Запад предоставил Ното самому себе, своей квазидуховности (рассудку, воображению, желанию и капризу), отбросив божественное измерение его присутствия в мире; через труд соединил его с природой и через труд таки удалил его из природы, сделав при этом ее врагом (!); поместив его в социальную семью, вскоре максимально освободил от «пут» этого самого социума. Но самое, пожалуй, важное состоит в том, что, будучи вооруженным наукой и техникой, «западоид» (А. А. Зиновьев) объявил всю предшествующую эволюцию человека тупиковой, а значит, ложной. То есть, от- 
вергая разнообразный опыт других народов и цивилизаций, он предложил свой исключительный, по меркам истории, антропологический марафон всеобщим достоянием человечества. Иначе говоря, ценности «западоида» объявлены ценностями всего человечества.

Но положение о доминировании технологий при переходе человека в постчеловеческое состояние тем не менее заметно модифицируется, если ввести в рассмотрение переменную экономики (рынка). Не секрет, что ранее ей уделяли внимание представители разных социальных наук, в том числе социальной психологии [Фромм 2009: 106-279], культурологии [Бодрийяр 2007] и экономики [Олсон 2007: 63-75]. В конце концов, эта проблема четко артикулирована в виде принциипа раскрепощения природы человека при помощи рынка, а именно идеологии laissez faire. Конечно, эта идеология видоизменилась на пути от классического через неклассический - к постнеклассическому капитализму (Ф. Г. Федотова). Нынешний же рынок предстает в модифицированном виде, а именно - как новый тип репрезентации его процессов посредством медиа. Между тем в постмодернистском культурном пространстве и рынок, и медиа образуют «две системы кодов отождествления таким образом, что дают возможность либидинальным энергиям одной системы накрыть другую систему, не создавая при этом... синтеза, нового объединения, нового языка или чего-нибудь такого» [Джеймисон 2008: 310].

Но этот вывод тем более интересен в свете представления постнеклассической философии науки о том, что абсолютные пределы управляемости Вселенной отсутствуют, то есть нет никакого конечного числа фундаментальных законов, при помощи которых разворачиваются процессы в неживой, живой и социально организованной формах движения материи. Значит, синтез технологии и рынка возможен в точке социальной бифуркации, как в принципе возможна новая тотализация вида Ното. Однако понятно и другое: пока несращенные социальные структуры будут и дальше порождать хаос, в качестве лона рождения упорядоченности post-Homo. Для примера сошлюсь на работу шведских интеллектуалов А. Барда и Я. Зодерквиста.

В информационном обществе, как считают эти теоретики, наиболее важным элементом будет «портал власти», или связующее звено всеобъемлющей сети. Вокруг него и формируется Netoкратия, способная к артикуляции адекватных аттракторов [Бард, Зодерквист 2004: 58]. Нисколько не скрывая своих намерений, они утверждают, что нетократия должна управлять «низшим классом, манипулируя тем, что можно назвать потребляющей деятельностью консьюмтариата, деятельностью, вызванной желаниями» [Там же: 147]. Умело используя схему реклама + потребитель = желание, можно решить две задачи: привязать консьюмтариат к наркотическому потребительству; тем самым дистанцироваться от него. На этом пути должны быть отброшены любые институты, содержащие гуманистический принцип, не говоря уже о нем самом. Напротив, в духе идей Ч. Дарвина и Ф. Ницше это общество просто обязано пройти сквозь «естественный отбор» и сформировать нетократическую наследственность. Она не чета прежним формам социального воспроизводства (семья, трудовые коллективы), тормозившим развитие как таковое. Все это нуждается в одной важной поправке - отбор будет контролируемым, но не большинством, а «нетократическими дивидуалами».

Этот антропологический ракурс также ценен для понимания всего нетократического проекта. У А. Барда и Я. Зодерквиста указывается на то, что в инфор- 
мационном обществе «развитие личности идет по пути реализации всех возможных состояний человека делимого, создания прагматичного союза различных темпераментов и черт характера». И далее - самое интересное: «...шизофреническая, калейдоскопическая личность... становится достойным подражания параметром, поскольку она функциональна» [Бард, Зодерквист 2004: 206] ${ }^{6}$. Но этот прагматический союз будут создавать именно нетократы, главная цель которых замена сетью человека в качестве великого общественного проекта - не выглядит шизофренически. Также не выглядит шизофренически заявление о том, что с такими онтологическими параметрами (иерархией во главе с нетократией, процедурами недемократического принятия решений, созданием режима диктатуры желаний для низшего класса - консьюмтариата, культивированием в человеке прогрессивно расщепляемой сущности) информационное общество «не тоталитарно» [Там же: 211] (!).

Объективная оценка этого проекта говорит о другом: перед нами не только манипулятивные процедуры ${ }^{7}$, но и, возможно, рождение новой, информационной разновидности тоталитаризма. Во-первых, нетократическая сетевая власть не обеспечивает ту «меру свободы» (Ж.-Л. Нанси), которую несли в себе иерархические структуры прежних обществ; во-вторых, она выводит из игры человека, заменяя его «шизиком» и предоставляя ему иные, негуманные правила игры; в-третьих, она искусственно создает консьюмтариат, участь которого - жить в мире репрессированной чувственности и иллюзорных желаний. Что же касается самой информации как новой «субстанции» для развертывания всех процессов, включая антроподинамические, то о ней есть мнение как о «самой совершенной эссенции лжи, которую будет загонять “шприц", воткнутый в мозги человечества» [Джемаль 2008: 73]. Причем лжи, являющейся рыночным брендированным (изысканным) товаром.

Отсюда напрашивается предварительный вывод: современный западный человек вступил на стезю технологического и рыночного саморасщепления, в начале пути рационально и деятельностно преодолев конечный набор принципов (например, Декалог) организации своего бытия, а затем перешел к самообольщению через миражи беспредельности ${ }^{8}$. Преодоление сложившейся ситуации видится диаметрально противоположным образом: или в программе примитивизма (добровольное сокращение человечества в 2000 раз, полное уничтожение технических устройств, расселение оставшихся 30 млн в тропических областях для воссоздания донеолитической социальности [Зерзан 2007]); или в программе симбиозных человеко-роботов, живущих и находящих смысл в киберпространстве и интерьере рынка.

6 Хочу заметить, что формализация наличного антропологического сюжета удачно проделана А. Г. Дугиным. Диагностируя нынешний постлиберально/постмодернистский гротеск, он показал, что «дивидуум», или случайное игровое сочетание частей человека (его органов, его клонов, его симулякров вплоть до киборгов и мутантов), выступает сегодня мерой всех вещеей [Дугин 2009: 43].

${ }^{7}$ Согласно теории манипуляции сознанием С. Г. Кара-Мурзы, вариант взаимодействия, при котором «один участник жизненной драмы заставляет других действовать в его интересах и по его программе так, что это не распознается жертвами и не вызывает у них сопротивления», должен быть квалифицирован как манипулятивный [Кара-Мурза 2000: 12].

${ }^{8}$ Программный доклад Римского клуба «Пределы роста» кроме экологического и социального контекстов имеет подчеркнуто антропологический смысл: современный человек должен культивировать процедуры самоограничения, считаясь с относительно замкнутыми глобальными процессами. 
И поскольку эти две тенденции неравновелики (неравноценны как для Ното, так и для post-Homo), а тем более их нельзя отождествить со странной аттрактивностью, то приходится ждать постмодернистский «великий Отказ», где субъект Отказа утверждает свой объект в контрапункте технологии и рынка. В противном случае многократные объемы инвестиций в робототехнику в сочетании с достижениями в области «больших данных», сетевых технологий, материаловедения и искусственного интеллекта [Росс 2017: 51] сделают человеческие фантасмагории о постчеловеческом реальностью. И так родится супер-аттрактор в виде постНото вместо Ноmo noosphericusa и ноосферного будущего.

\section{Лuтература}

Бард А., Зодерквист Я. NЕТОКРАТИЯ. Новая правящая элита после капитализма. СПб. : Стокгольмская школа экономики в Санкт-Петербурге, 2004.

Бодрийяр Ж. К критике политической экономии знака. М. : Академический Проект, 2007.

Буровский А. М. После человека / Т. Ю. Чеснокова // Постчеловек. От неандертальца к киборгу. М. : Алгоритм, 2008.

Гуревич П. С. Философия человека. М. : ИФ РАН, 1999. Ч. 1.

Делягин М. Г. Драйв человечества. Глобализация и мировой кризис. М. : Вече, 2008.

Демиденко Э. С. Ноосферное восхождение земной жизни. М. : МАОР, 2003.

Дери М. Скорость убегания: Киберкультура на рубеже веков. М. : АСТ Москва, 2008.

Джеймисон Ф. Постмодернізм, або Логіка культури пізнього капіталізму. Київ : Видавництво «Курс», 2008.

Джемаль Г. Наследие Кириллова / Т. Ю. Чеснокова // Постчеловек. От неандертальца к киборгу. М. : Алгоритм, 2008.

Дугин А. Г. Четвертая политическая теория. Россия и политические идеи XXI века. СПб. : ТИД Амфора, 2009.

Дэвис Э. Техногнозис: миф, магия и мистицизм в информационную эпоху. Екатеринбург : Ультра. Культура, 2008.

Зерзан Дж. Первобытный человек будущего. М. : Гилея, 2007.

Кара-Мурза С. Г. Манипуляция сознанием. М. : Алгоритм, 2000.

Князева Е. Н. «Я» как динамическая структура-процесс // Синергетика: человек, общество. М. : Изд-во РАГС, 2000.

Кутырев В. А. Человеческое и иное: борьба миров. СПб. : Алетейя, 2009.

Кутырев В. А. Философия трансгуманизма: учебно-методическое пособие. Нижний Новгород : Нижегородский университет, 2010.

Лазарев Ф. В. Современная цивилизация: ноосферно-антропологический проект // Человек и современная цивилизация: сб. ст. Симферополь : Доля, 2008.

Лебедев С. А., Лазарев Ф. В. Многомерный человек: онтология и методология исследования. М. : Изд-во Московского ун-та, 2010.

Муза Д. Е. Информационное общество: притязания, возможности, проблемы. Философские очерки: монография. Днепропетровск : Адверта, 2013. 
Назаретян А. П. Нелинейное будущее. Мегаистория, синергетика, культурная антропология и психология в глобальном прогнозировании: монография. М. : АргамакМедиа, 2017.

Олсон М. Влада і процвітання. Подолання комуністичних і капіталістичних диктатур. Київ : Вид. дім «Києво-Могилянська Академія», 2007.

Росс А. Индустрии будущего. М. : АСТ, 2017.

Табачковський В. Г. Полісутнісне hото: філософсько-мистецька думка в пошуках „неевклідової рефлективності”. Київ : Видавець ПАРАПАН, 2005.

Тейяр де Шарден П. Феномен человека. М. : Гл. ред. изданий для зарубежных стран изд-ва «Наука», 1987.

Тоффлер А. Футурошок. СПб. : Лань, 1997.

Тоффлер Э. Революционное богатство. М. : АСТ: АСТ Москва: Профиздат, 2008.

Фромм Э. Здоровое общество. М. : АСТ: АСТ Москва, 2009.

Фукуяма Ф. Наше постчеловеческое будущее: Последствия биотехнологической революции. М. : АСТ: Люкс, 2004.

Хабермас Ю. Будущее человеческой природы. На пути к либеральной евгенике? М. : Весь мир, 2002.

Хоружий С. С. Глобалистика и антропология [Электронный ресурc]. URL: http:// synergia-isa.ru/wp-content/uploads/2009/hor_interelig_rus.doc.

Шапиро Р. Прогноз на будущее. М. : АСТ: АСТ Москва, 2009. 